\title{
Adequacy of nutritional intake among older men living in Sydney, Australia: findings from the Concord Health and Ageing in Men Project (CHAMP)
}

\author{
Rosilene V. R. Waern 1,2,3,*, Robert G. Cumming ${ }^{2,3}$, Fiona Blyth ${ }^{1}$, Vasi Naganathan ${ }^{1}$, \\ Margaret Allman-Farinelli ${ }^{4}$, David Le Couteur ${ }^{1}$, Stephen J. Simpson ${ }^{5}$, Hal Kendig ${ }^{3}$ and Vasant Hirani ${ }^{1,2,3}$ \\ ${ }^{1}$ Centre for Education and Research on Ageing, Concord Hospital, University of Sydney, Sydney, NSW 2139, Australia \\ ${ }^{2}$ School of Public Health, University of Sydney, Sydney, NSW 2006, Australia \\ ${ }^{3}$ ARC Centre of Excellence in Population Ageing Research (CEPAR), University of New South Wales, NSW 2033, Australia \\ ${ }^{4}$ School of Molecular Bioscience, University of Sydney, Sydney, NSW 2008, Australia \\ ${ }^{5}$ Charles Perkins Centre, University of Sydney, Sydney, NSW 2006, Australia
}

(Submitted 17 December 2014 - Final revision received 5 June 2015 - Accepted 5 June 2015)

\section{Abstract}

Previous research shows that older men tend to have lower nutritional intakes and higher risk of under-nutrition compared with younger men. The objectives of this study were to describe energy and nutrient intakes, assess nutritional risk and investigate factors associated with poor intake of energy and key nutrients in community-dwelling men aged $\geq 75$ years participating in the Concord Health and Ageing in Men Project - a longitudinal cohort study on older men in Sydney, Australia. A total of 794 men (mean age 81.4 years) had a detailed diet history interview, which was carried out by a dietitian. Dietary adequacy was assessed by comparing median intakes with nutrient reference values (NRV): estimated average requirement, adequate intake or upper level of intake. Attainment of NRV of total energy and key nutrients in older age (protein, Fe, Zn, riboflavin, $\mathrm{Ca}$ and vitamin D) was incorporated into a 'key nutrients' variable dichotomised as 'good' ( $\geq 5$ ) or 'poor' ( $\leq 4)$. Using logistic regression modelling, we examined associations between key nutrients with factors known to affect food intake. Median energy intake was $8728 \mathrm{~kJ}$ $(\mathrm{P} 5=5762 \mathrm{~kJ}, \mathrm{P} 95=12303 \mathrm{~kJ})$, and mean BMI was $27.7(\mathrm{sD} 4.0) \mathrm{kg} / \mathrm{m}^{2}$. Men met their NRV for most nutrients. However, only $1 \%$ of men met their NRV for vitamin D, only $19 \%$ for Ca, only $30 \%$ for K and only $33 \%$ for dietary fibre. Multivariate logistic regression analysis showed that only country of birth was significantly associated with poor nutritional intake. Dietary intakes were adequate for most nutrients; however, only half of the participants met the NRV of $\geq 5$ key nutrients.

\section{Key words: Dietary intake: Elderly: Dietary requirements: Males}

Population ageing is a global phenomenon influencing health patterns in nearly all countries ${ }^{(1)}$. In Australia, the population aged 65 years and over is increasing rapidly as a result of the ageing of the large post-war baby boom cohort, increasing life expectancy at age 65 years ${ }^{(2)}$. Furthermore, the composition of the older population has been shifting with increasing proportions of men reaching advanced old age as well as the ageing of migrants including many who had arrived from Europe during the 1950s and 1960s. From 2012 to 2061, it is projected that the proportion of people aged 65 years and over will increase from 14 to $25 \%$ and the proportion of people aged 85 years and over will increase by $4.2 \%$ with a notable increase in the proportion of men in this age group (from 35 to up to $46 \%)^{(3)}$.

It is well known that diet is an important modifiable factor affecting the maintenance of health in old age ${ }^{(4)}$. Adequate nutritional intake is associated with reduced morbidity and mortality as well as improved quality of life in older age ${ }^{(5)}$. An Australian longitudinal survey recently reported that nutrition at baseline was an independent predictor of older people's 'ageing well', defined as continuing to live in the community with independence in daily living and with good self-rated health and psychological well-being ${ }^{(6)}$. Nutritional requirements of older people are the same, if not greater, compared with younger adults ${ }^{(7)}$. However, older people tend to have lower dietary intakes compared with their younger counterparts ${ }^{(7-10)}$.

Decline in dietary intake is related to physiological, socialeconomical and psychological changes observed in older people, and may increase the risk of nutritional inadequacy ${ }^{(10-15)}$. Factors such as country of origin ${ }^{(16)}$, living conditions ${ }^{(15,17)}$ and physical disability $^{(18)}$ increase the likelihood of nutritional inadequacy. Older men are at even higher risk of nutritional inadequacy than women due to their limited involvement in the planning and preparation of meals ${ }^{(19)}$.

Although dietary habits have been reported for older men in Europe and North America, there have been limited studies on the dietary intake of older men in Australia ${ }^{(20,21)}$. This is of

Abbreviations: CHAMP, Concord Health and Ageing in Men Project; NRV, nutrient reference values; PAL, physical activity level; UL, upper level.

* Corresponding author: R. V. R. Waern, email rosie.waern@sydney.edu.au 
concern when considering the predicted increase in the number of older men living in Australia.

The primary aim of the present study was to describe and assess the risk of not meeting the requirements for energy and nutrient intakes among community-dwelling men aged 75 years and over living in Sydney, Australia. The secondary aim was to investigate factors associated with having a poor intake of key nutrients in older age.

\section{Methods \\ Participants}

The Concord Health and Ageing in Men Project (CHAMP) is a longitudinal cohort study of the health of older men based in Sydney, Australia, which has followed-up men aged 70 years and over since $2005^{(22)}$. In 2012, collection of nutritional data using a diet history methodology was added to the third wave of CHAMP data collection (5-year follow-up).

The original selection of CHAMP subjects has been described in detail elsewhere ${ }^{(22)}$. In brief, 3005 men aged 70 years and over living in the suburbs of Burwood, Canada Bay and Strathfield in Sydney, Australia, who were on the electoral roll were invited to participate in CHAMP. A total of 1705 men participated in the project during the baseline data collection phase in 2005-2007. The only exclusion condition was living in a residential aged care facility. Participants completed a questionnaire at home (approximately $45 \mathrm{~min}$ to complete) and then attended a clinic (approximately $3 \mathrm{~h}$ to complete) where further data were collected through interview and examination.

A total of 954 participants took part in the 5-year follow-up assessment. Of the 751 men who did not complete the 5-year follow-up, the majority were either deceased (51\%) or too ill ( $23 \%)$ to attend the study clinic. For the nutritional component of the study, 794 ( $83 \%$ ) of them agreed to participate. Of the $160(17 \%)$ non-respondents, $49 \%$ stated that they were too busy or not interested, $19 \%$ were deceased, $16 \%$ were too ill/ not able, 5\% were not reachable, 5\% had limited English literacy, $4 \%$ had moved away from the study area and $2 \%$ had withdrawn completely from the study. Respondents were significantly younger, more likely to be married, more likely to have a higher education level and more physically active than non-respondents, but did not significantly differ in terms of age, country of birth, occupational history, income or self-rated health.

\section{Diet history}

Usual dietary intake was determined through collection of diet histories $^{\text {(23) }}$, conducted by a research dietitian at the participant's residence using a standardised diet history method between August 2010 and August 2013, covering all the seasonal variations. The diet history questionnaire form (open-ended questions on food consumption at different meal times) used in CHAMP was adapted from the Sydney South West Area Health Service outpatient's diet history form. Participants were asked questions about their usual dietary intake during the previous 3 months, and quantities of foods consumed were ascertained by means of food models, photographs ${ }^{(24)}$ and household measures - for example, cup size. A checklist of common food items was included to verify those food items often forgotten. Validity of this dietary record has previously been reported by comparison with a 4-d weighed food record collected in a subgroup of fifty-six CHAMP men ${ }^{(25)}$. The diet history interview took an average of $45 \mathrm{~min}$ to be completed. Participants' wives, carers and/or family members were encouraged to be present during the interview as this has been found to assist participants' ability to recall ${ }^{(19)}$

\section{Misreporting}

CHAMP participants' activity levels were measured using the Physical Activity Scale for the Elderly (PASE) $^{(26)}$, which uses a different scoring system to physical activity level (PAL). It was not feasible to convert PASE scores to PAL; instead, data of participants who reported energy intakes above or below $2 \mathrm{SD}$ from the median energy intake ( $n$ 33) were excluded because of probable under- and over-reporting. The final sample, therefore, contained 761 men aged 75 years or older.

\section{Data handling}

Participants' daily dietary intakes were converted into nutrient intakes using FoodWorks 7 Professional for Windows (Xyris Software (Australia) Pty Ltd), which uses the Australian Food, Supplement and Nutrient Database 2007 (AUSNUT 2007) that contains thirty-seven nutrient values for 4425 foods $^{(27)}$. Nutrient values for vitamin $\mathrm{B}_{6}$ and $\mathrm{B}_{12}$ are not included in this database, and therefore were not assessed. Vitamin D values from AUSNUT 2007 are to be interpreted with caution as data were derived from a small set of analyses and values were based on a number of assumptions $^{(28)}$. Na intakes reported in this study include $\mathrm{Na}$ naturally present in foods as well as $\mathrm{Na}$ added during processing, but excludes the 'discretionary salt' added by participants in home-prepared foods or 'at the table'. A coding manual was developed to assure consistent data entry of the diet history questionnaire, where 869 food items were identified and standardised. Standardising food coding involved looking for described food items in the FoodWorks' database (AUSNUT 2007), selecting the closest possible options and recording respective entries used in FoodWorks for future reference. Recipes of uncommonly consumed dishes were entered separately using specific ingredients and amounts described by participants. Recipes of commonly consumed foods were entered as the closest possible option. Takeaways and pre-prepared (e.g. meals on wheels) dishes were identified and entered according to the information provided on the restaurant menu/package/website. Consumed leftovers were entered according to participants' descriptions of amounts and frequency. Dietary supplements consumed as meal replacement or snacks (e.g. TwoCal HN; Abbott Nutrition) were entered accordingly. Foods consumed in different seasons (outside the 3-month cut-off) were not taken into consideration, as they would not reflect the usual intake of the past 3 months. The median daily dietary intakes of energy, fat, protein, carbohydrates, alcohol, dietary fibre, thiamin, riboflavin, niacin and dietary folate equivalents, vitamins $\mathrm{A}, \mathrm{C}, \mathrm{D}, \mathrm{E}, \mathrm{Ca}, \mathrm{Fe}$, $\mathrm{Zn}, \mathrm{Mg}, \mathrm{P}, \mathrm{K}, \mathrm{I}$ and $\mathrm{Na}$ were calculated for each participant. Estimated energy requirements were calculated using $\mathrm{BMR}^{(29)}$ 
multiplied by the PAL of 1.6 (light activity) for older men ${ }^{(30)}$. Percentage of energy derived from fat, protein, carbohydrates and alcohol was calculated. Intake of protein was also expressed per kg of body weight.

The Australian nutrient reference values (NRV) consist of a set of evidence-based nutritional recommendations. The median dietary intake of each nutrient in the CHAMP data set was compared with the NRV for males aged 70 years and over as follows: estimated average requirement (EAR) or adequate intake (AI) when recommended dietary intake - and consequently EAR - had not been established; upper level (UL) of intake to assess excessive Na intake. Acceptable macronutrient distribution range (AMDR) - amount of macronutrients (as a percentage of contribution to energy) was used to assess appropriate intake of macronutrients ${ }^{(30)}$. To measure acceptable percentage contribution to energy (\%) from alcohol, we used the recommendations from the Australian dietary guidelines ${ }^{(31)}$. Prevalence of inadequate intakes was calculated by comparing the group's usual intake with corresponding $\mathrm{NRV}^{(32)}$

Total energy is not a nutrient but it is necessary for a number of essential activities in the body ${ }^{(30)}$. From this point onwards, we will refer to energy as a dietary component. Total energy and six nutrients have been identified as of particular importance in older age, and they are as follows: protein, $\mathrm{Fe}, \mathrm{Zn}$, riboflavin, $\mathrm{Ca}$ and vitamin $\mathrm{D}^{(5)}$. To investigate the proportion of men meeting the requirements for these dietary components, and to determine some of the factors associated with their poor nutritional intake, a composite key nutrients intake variable was created. This variable was dichotomised as 'poor' (meets the requirements of four or fewer nutrients) and 'good' (meets the requirements of five or more nutrients).

Foods included in the AUSNUT 2007 $7^{(27)}$ have an assigned name, food description, inclusions, exclusions and an eightdigit code; these eight-digit food codes are grouped into major, sub-major and minor groups ${ }^{(28)}$. The sub-major food group was used to identify the three main food sources of each nutrient for all the men included in the analysis.

\section{Measurements}

Information on socio-demographic and economic factors, smoking status, alcohol consumption, physical activity and other factors known to affect food intake were obtained through a self-completed questionnaire. Height and weight were measured according to a standardised protocol, and BMI was calculated as $\mathrm{kg} / \mathrm{m}^{2}$. BMI was categorised as underweight $\left(<22 \mathrm{~kg} / \mathrm{m}^{2}\right)$, normal $\left(22-30 \mathrm{~kg} / \mathrm{m}^{2}\right)$ and overweight/obese $\left(>30 \mathrm{~kg} / \mathrm{m}^{2}\right)$ in accordance with recent studies in older people ( 65 years and over) that have shown that there is an increased risk of mortality in the lowest and highest cut-offs ${ }^{(33-38)}$. Country of birth was grouped as Australia and New Zealand, Italy and Greece and other. Source of income was categorised as age pension only and other (repatriation pension, veteran's pension, superannuation or other private income, own business/ farm/partnership, wage or salary, other or any source of income combination). We used source of income as a proxy of personal income, assuming that age pensioners had the lowest income. Self-rated health was obtained through response to the question 'compared to other people of your own age, how would you rate your own health?', and data were dichotomised into excellent/good $v$. fair/poor/very poor. Participants were asked about change in their eating patterns in the past 5 years and whether they had any financial issues in the last 12 months that prevented them from buying food.

Data on medical conditions were obtained from a selfreported questionnaire in which participants reported whether a doctor or a health care provider had told them that they had any of the following diseases: diabetes, thyroid problems, osteoporosis, Paget's disease, stroke, Parkinson's disease, kidney stones, dementia, depression, epilepsy, hypertension, myocardial infarction, angina, heart failure, intermittent claudication, chronic obstructive lung disease, liver disease, chronic kidney disease, arthritis and cancer (excluding non-melanotic skin cancer and benign tumours such as bowel polyps and meningioma). Multi-morbidity was defined as having two or more of these conditions ${ }^{(39)}$.

\section{Statistical analysis}

Nutritional adequacy was assessed by comparing participants' median intakes with the NRV recommended for males aged 71 years or older. A secondary analysis of the data was performed using the composite dichotomised key nutrients intake variable. The dichotomised key nutrients intake variable (poor or good) was used in a logistic regression model to examine associations with socio-demographic, economic, health, lifestyle and mealrelated activities of daily living factors.

Data were analysed using SAS version 9.3 (SAS Institute Inc.). A number of statistical methods (e.g. Shapiro-Wilk) were used to examine data distribution, and we found that all the nutrients analysed (except carbohydrate (\%E)) were not normally distributed; therefore, subjects' characteristics and energy and nutrient intakes were reported as medians and 5th (P5) and 95th (P95) percentiles when numerical values were obtained and as percentages when categorical values were obtained. Evidence against null hypotheses was considered statistically significant if $P$ values were $<0 \cdot 05$. The goodness of fit of the final adjusted logistic regression model was assessed using the Hosmer-Lemeshow statistic.

The data presented on vitamin and mineral intakes refer to food consumption only; intake through nutritional supplements was not assessed as data are unavailable at present.

\section{Results}

\section{Participants' characteristics}

Socio-demographic, economic, health risk and meal habitrelated information are presented in Table 1. Participants' mean age was $81 \pm 4.4$ years, and a total of $57 \%$ were 80 years or older. Mean BMI was 27.7 (SD 4.0 ) kg/m², with a total of $27 \%$ of the men categorised as overweight/obese, $67 \%$ as normal and $6 \%$ as underweight. The majority of men were married (75\%), lived with someone ( $80 \%$ ), received other than just age pension as source of income (61\%) and were born in Australia or New Zealand (54\%). Most men considered their health as excellent or good $(75 \%)$ in spite of living with two or more 
Table 1. Participants' descriptive characteristics (Mean values and standard deviations; number of subjects and percentages)

\begin{tabular}{|c|c|c|}
\hline Socio-demographic and economic factors & $n$ & $\%$ \\
\hline \multicolumn{3}{|l|}{ Age (years) $(n 761)$} \\
\hline $75-79$ & 327 & 43 \\
\hline $80-84$ & 277 & 36 \\
\hline $85+$ & 157 & 21 \\
\hline Mean & \multicolumn{2}{|c|}{81} \\
\hline SD & \multicolumn{2}{|c|}{4.4} \\
\hline \multicolumn{3}{|l|}{ Source of income ( $n 758)$} \\
\hline Pension only & 296 & 39 \\
\hline Other* & 462 & 61 \\
\hline \multicolumn{3}{|l|}{ Occupational history ( $n 757$ ) } \\
\hline Non-physical work $\dagger$ & 632 & 84 \\
\hline Plant and machine operator/labourer & 125 & 16 \\
\hline \multicolumn{3}{|l|}{ Marital status $(n 761)$} \\
\hline Divorced/separated/widowed/never married/other & 187 & 25 \\
\hline Married/de facto & 574 & 75 \\
\hline \multicolumn{3}{|l|}{ Living arrangements ( $n 761$ ) } \\
\hline Lives alone & 152 & 20 \\
\hline Live with others & 607 & 80 \\
\hline \multicolumn{3}{|l|}{ Post-school qualifications ( $n$ 757) } \\
\hline Bachelor's degree or higher & 119 & 16 \\
\hline Other & 638 & 84 \\
\hline \multicolumn{3}{|l|}{ Country of birth ( $n 761)$} \\
\hline Australia/New Zealand & 410 & 54 \\
\hline Italy/Greece & 178 & 23 \\
\hline Other & 173 & 23 \\
\hline \multicolumn{3}{|l|}{ Health and lifestyle factors } \\
\hline \multicolumn{3}{|l|}{ PASE $(n 759)$} \\
\hline Low activity $(\leq 76)$ & 250 & 33 \\
\hline Median activity $(77-160)$ & 255 & 34 \\
\hline High activity $(\geq 161)$ & 254 & 33 \\
\hline Mean & \multicolumn{2}{|c|}{$120 \cdot 2$} \\
\hline SD & \multicolumn{2}{|c|}{62.0} \\
\hline \multicolumn{3}{|l|}{ BMI $\left(\mathrm{kg} / \mathrm{m}^{2}\right)(n 738)$} \\
\hline Underweight $(<22.0)$ & 44 & 6 \\
\hline Normal $(22.0-30.0)$ & 502 & 67 \\
\hline Overweight/obese $(>30.0)$ & 199 & 27 \\
\hline Mean & \multicolumn{2}{|c|}{27.7} \\
\hline SD & \multicolumn{2}{|c|}{4.0} \\
\hline \multicolumn{3}{|l|}{ Alcohol consumption ( $n$ 761) } \\
\hline$>14$ drinks/week & 114 & 15 \\
\hline$\leq 14$ drinks/week & 470 & 62 \\
\hline Non-drinker & 177 & 23 \\
\hline Cigarette smoking ( $n$ 753) & & \\
\hline Current smoker & 24 & 3 \\
\hline Former smoker/never smoked & 729 & 97 \\
\hline Self-rated health $(n 761)$ & & \\
\hline Fair/poor/very poor & 194 & 25 \\
\hline Excellent/good & 567 & 75 \\
\hline Multi-morbidity ( $n 759)$ & & \\
\hline$\geq 2$ & 545 & 72 \\
\hline Other factors & & \\
\hline Able to grocery shop ( $n 759)$ & & \\
\hline No & 14 & 2 \\
\hline Yes & 745 & 98 \\
\hline Able to prepare own meals $(n 759)$ & & \\
\hline No & 32 & 4 \\
\hline Yes & 727 & 96 \\
\hline Meal service (e.g. MOW) ( $n$ 759) & & \\
\hline Yes & 24 & 3 \\
\hline No & 735 & 97 \\
\hline
\end{tabular}

PASE, Physical Activity Scale for the Elderly; MOW, meals on wheels.

* Repatriation pension/veteran's pension, superannuation or other private income, own business/farm/partnership, wage or salary, other or any source of income combination.

† Manager/professional/para-professional/tradesperson/clerk/salesperson/ personal-service worker/inadequately stated/unknown.

‡ Trade/apprenticeship/certificate/diploma/no qualifications. morbidities (72\%). Few men were unable to shop for groceries (2\%) or prepare their own meals ( $4 \%$ ), and only $3 \%$ had received some kind of meal service in the previous year. Alcohol consumption was most likely to be at a safe level (62\%) and very few men were current smokers (3\%).

When asked about changes in their dietary intake over the past 5 years, $77 \%$ of the participants reported no change in their diet. Only $1 \%$ of the participants responded yes when asked the question 'in the past 12 months, was there any time when you could not afford to buy food?'.

\section{Dietary intake}

Table 2 shows the median values and 5th/95th percentiles intake of each studied nutrient, the proportion of participants not meeting NRV and the three main food sources of each nutrient.

Participants' median daily intake of total energy was $8728 \mathrm{~kJ}$ $(\mathrm{P} 5=5762 \mathrm{~kJ}, \mathrm{P} 95=12303 \mathrm{~kJ})$, and there was no significant difference in intakes between age groups (data not shown). Median macronutrient distribution is presented in Fig. 1. Participants' median percentage contribution of protein to energy was within the NRV; participants' median carbohydrate contribution to energy was below the AMDR, whereas their median total and saturated fat intakes were above their respective AMDR. Most participants' median micronutrient intakes reached their respective NRV, with only $\mathrm{Ca}$, K, vitamin $\mathrm{D}$ and vitamin $\mathrm{E}$ intakes being below their respective NRV. Participants' vitamin D median intake (32.5\% of NRV) was the lowest compared with its NRV, followed by Ca (73\% of NRV) and $\mathrm{K}$ ( $87 \%$ of NRV). Although participants' median intakes of nutrients such as $\mathrm{Fe}, \mathrm{P}$, niacin and vitamin $\mathrm{C}$ were more than double of what is recommended, median intakes did not exceed UL of intake.

\section{Dietary adequacy and food sources}

The majority of participants met the NRV for energy, protein per kg of body weight, thiamin, riboflavin, niacin, folate, vitamin A, vitamin $\mathrm{C}, \mathrm{Fe}, \mathrm{Zn}, \mathrm{P}$ and I (Table 2). Nutrients of particular concern were vitamin $\mathrm{D}, \mathrm{Ca}, \mathrm{K}$ and dietary fibre, for which less than half of the participants met their requirements. Although the median intake of $\mathrm{Na}$ was below the UL of intake, $31 \%$ of the participants were consuming amounts considered harmful - that is, above UL. Two-thirds of the participants were consuming saturated fat amounts above the recommended intakes.

Milk was among the main food sources of many nutrients such as protein, $\mathrm{Ca}$, vitamin $\mathrm{D}$ and $\mathrm{P}$. Breakfast cereal was the second most predominant food source and provided participants with nutrients such as thiamin, folate and Fe.

\section{Factors associated with poor intakes of key nutrients}

A total of $48 \%$ ( $n$ 362) of the participants were considered to have a poor nutritional intake, based on meeting recommendations for four or fewer of the seven key nutrients of interest for older adults (total energy, protein, Fe, Zn, riboflavin, Ca and vitamin D). At the univariate level (Table 3), country of birth $(P>0.0001)$, source of income $(P=0.002)$ and occupational 
Table 2. Median daily intake of energy and nutrients, proportion of participants not meeting the recommended intake and main food sources of each nutrient (Median values and 5th/95th percentiles; percentages and number of subjects)

\begin{tabular}{|c|c|c|c|c|c|c|}
\hline & \multirow{2}{*}{$\begin{array}{l}\text { Recommended intake } \\
\text { (male, } \geq 70 \text { years old) }\end{array}$} & \multirow[b]{2}{*}{ Median } & \multirow[b]{2}{*}{ P5/P95 } & \multicolumn{2}{|c|}{$\begin{array}{l}\text { Not meeting } \\
\text { recommended intake }\end{array}$} & \multirow[b]{2}{*}{ Main food sources } \\
\hline & & & & $\%$ & $n$ & \\
\hline \multicolumn{7}{|l|}{ Energy and macronutrients } \\
\hline Total energy $(\mathrm{kJ} / \mathrm{d})-E E R^{*} \dagger$ & - & $8728 \cdot 0$ & $5762 \cdot 3 / 12303 \cdot 0$ & 28 & 211 & Olive oil, milk, cheese \\
\hline Protein $(\mathrm{g} / \mathrm{kg}$ per $\mathrm{d})-\mathrm{EAR} \dagger$ & 0.86 & $1 \cdot 3$ & $0.78 / 2 \cdot 05$ & 9 & 74 & \\
\hline Protein $(\mathrm{g} / \mathrm{d})$ & - & $99 \cdot 3$ & $63 \cdot 3 / 146 \cdot 6$ & - & - & Beef, chicken, milk \\
\hline Protein $(\% \mathrm{E} / \mathrm{d})-\mathrm{AMDR}$ & $15-25$ & $19 \cdot 4$ & $13 \cdot 8 / 26 \cdot 7$ & 16 & $125 \ddagger$ & \\
\hline Carbohydrate $(\mathrm{g} / \mathrm{d})$ & - & $199 \cdot 0$ & $119 \cdot 7 / 303 \cdot 9$ & - & - & \\
\hline Carbohydrate $(\% \mathrm{E} / \mathrm{d})-\mathrm{AMDR}$ & $45-65$ & $37 \cdot 7$ & $24 \cdot 9 / 50 \cdot 6$ & 82 & $626 \S$ & Banana, rice, pasta \\
\hline Total fat $(\mathrm{g} / \mathrm{d})$ & - & $82 \cdot 3$ & $42 \cdot 2 / 142 \cdot 6$ & - & - & \\
\hline Total fat $(\% \mathrm{E} / \mathrm{d})-\mathrm{AMDR}$ & 20-35 & $35 \cdot 0$ & $23 \cdot 3 / 49 \cdot 6$ & 48 & $369 \|$ & Olive oil, cheese, milk \\
\hline Saturated fat $(\mathrm{g} / \mathrm{d})$ & - & $27 \cdot 8$ & $13 \cdot 6 / 50 \cdot 7$ & - & - & \\
\hline Saturated fat $(\% \mathrm{E} / \mathrm{d})-\mathrm{AMDR}$ & $<10$ & $11 \cdot 8$ & $7 \cdot 4 / 18 \cdot 3$ & 67 & 508 & Cheese, milk, butter \\
\hline Dietary fibre $(g / d)-A l$ & 30 & $26 \cdot 0$ & $14 \cdot 2 / 45 \cdot 5$ & 67 & 511 & Peas, banana, carrot \\
\hline Alcohol (g/d) & - & 4.8 & $0 / 37 \cdot 2$ & - & - & \\
\hline Alcohol (\%E/d) - ADG & $<5$ & 1.7 & $0 / 14 \cdot 0$ & - & - & Beer, red wine, white wine \\
\hline \multicolumn{7}{|l|}{ Vitamins } \\
\hline Thiamin $(\mathrm{mg} / \mathrm{d})$ - EAR & 1 & $1 \cdot 6$ & $0 \cdot 8 / 3 \cdot 4$ & 12 & 91 & $\begin{array}{l}\text { Breakfast cereals, yeast } \\
\text { vegetable extracts, whole } \\
\text { grain bread }\end{array}$ \\
\hline Riboflavin (mg/d) - EAR & 1.3 & $2 \cdot 2$ & $1 \cdot 1 / 4 \cdot 3$ & 11 & 84 & $\begin{array}{l}\text { Milk, yeast vegetable extracts, } \\
\text { breakfast cereal }\end{array}$ \\
\hline Niacin equivalent $(\mathrm{mg} / \mathrm{d})-\mathrm{EAR}$ & 12 & $50 \cdot 0$ & $31 \cdot 5 / 78 \cdot 1$ & 0 & 1 & Chicken, beef, breakfast cereal \\
\hline $\begin{array}{l}\text { Dietary folate equivalent }(\mu \mathrm{g} / \mathrm{d})- \\
\text { EAR }\end{array}$ & 320 & $415 \cdot 7$ & $206 \cdot 5 / 850 \cdot 2$ & 29 & 223 & $\begin{array}{l}\text { Yeast vegetable extracts, } \\
\text { breakfast cereal, tea }\end{array}$ \\
\hline Vitamin A $(\mu \mathrm{g} / \mathrm{d})$ - EART & 625 & 976.8 & $430 \cdot 0 / 2112 \cdot 8$ & 17 & 126 & Carrot, sweet potato, milk \\
\hline Vitamin C $(\mathrm{mg} / \mathrm{d})-$ EAR & 30 & $106 \cdot 4$ & $40 \cdot 2 / 245 \cdot 9$ & 2 & 12 & Orange, orange juice, broccoli \\
\hline $\operatorname{Vitamin} D(\mu \mathrm{g} / \mathrm{d})-\mathrm{Al}^{\star \star}$ & 15 & 4.5 & $1 \cdot 9 / 9 \cdot 6$ & 99 & 752 & Fish, milk, cheese \\
\hline Vitamin E $(\mathrm{mg} / \mathrm{d})-\mathrm{Al} \dagger \dagger$ & 10 & 9.7 & $4 \cdot 3 / 21 \cdot 0$ & 53 & 403 & Olive oil, rapeseed oil, egg \\
\hline \multicolumn{7}{|l|}{ Minerals } \\
\hline $\mathrm{Ca}(\mathrm{mg} / \mathrm{d})-\mathrm{EAR}$ & 1100 & $800 \cdot 7$ & $390 \cdot 8 / 1540 \cdot 9$ & 80 & 610 & Milk, cheese, rolled oats \\
\hline $\mathrm{Fe}(\mathrm{mg} / \mathrm{d})-\mathrm{EAR}$ & 6 & $12 \cdot 8$ & $7 \cdot 6 / 22 \cdot 3$ & 1 & 7 & $\begin{array}{l}\text { Breakfast cereals, beef, whole } \\
\text { grain bread }\end{array}$ \\
\hline $\mathrm{Zn}(\mathrm{mg} / \mathrm{d})-\mathrm{EAR}$ & 12 & $13 \cdot 3$ & $7 \cdot 9 / 21 \cdot 2$ & 35 & 270 & Beef, breakfast cereal, cheese \\
\hline$M g(m g / d)-E A R$ & 350 & $350 \cdot 4$ & $214 \cdot 3 / 543 \cdot 4$ & 50 & 380 & Banana, milk, breakfast cereals \\
\hline$P(\mathrm{mg} / \mathrm{d})-E A R$ & 580 & $1583 \cdot 3$ & $975 \cdot 0 / 2376 \cdot 7$ & 0 & 1 & Milk, beef, cheese \\
\hline$K(m g / d)-A l$ & 3800 & 3323.3 & $2101 \cdot 1 / 5052 \cdot 1$ & 70 & 533 & Milk, banana, potato \\
\hline$I(\mu \mathrm{g} / \mathrm{d})-\mathrm{Al}$ & 100 & $110 \cdot 5$ & $49 \cdot 8 / 233 \cdot 9$ & 40 & 306 & Milk, egg, fish \\
\hline $\mathrm{Na}(\mathrm{mg} / \mathrm{d})-U L \neq \ddagger$ & 2300 & $1945 \cdot 7$ & $1033 \cdot 2 / 3422 \cdot 8$ & 31 & 237 & Ham, cheese, wholemeal bread \\
\hline
\end{tabular}

EER, estimated energy requirements; EAR, estimated average requirement; \%E, percentage contribution to energy; AMDR, accepted macronutrient distribution range; Al, adequate intake; ADG, Australian dietary guidelines; UL, upper level.

${ }^{*}$ EER will vary according to height, weight and physical activity level of each individual.

$\dagger$ Eight missing, one refusal and two unable to weigh.

$\ddagger$ Of the $16 \%$ of the participants not meeting the AMDR for protein (\%E), $46 \%(n 58)$ had an average intake below the AMDR and $54 \%$ ( $n 67)$ above the AMDR.

$\S$ All the participants $(n 626)$ not meeting the AMDR for carbohydrate (\%E) had an average intake below the AMDR.

\| Of the $48 \%$ of the participants not meeting the AMDR for total fat (\%E), 3\% (10) had an average intake below the AMDR and $97 \%$ (359) above the AMDR.

II Retinol equivalent.

** Vitamin D data should be interpreted with caution.

†† $a$-Tocopherol equivalents.

¥¥ Includes Na naturally present in foods as well as Na added during processing, but excludes the 'discretionary salt' added by participants in home-prepared foods or 'at the table'; inadequate intake refers to the proportion of participants who consumed amounts above the UL.

history $(P=0.02)$ were significantly associated with nutritional intake. Italian- or Greek-born men had an overall lower dietary intake of all the key nutrients. Although not reaching statistical significance, we found that current smokers $(P=0.06)$ and those who were unable to prepare their own meals $(P=0.09)$ had slightly higher risk of having a poor intake of key nutrients, whereas men with a university education had a slightly higher nutritional intake of key nutrients $(P=0.06)$.

A multivariate logistic regression analysis showed that only the association between country of birth and nutritional intake remained significant after adjustment for occupational history and source of income (Table 4). Participants born in Italy/ Greece were more likely to have poor nutritional intake of key nutrients (OR 1.94; $95 \%$ CI 1.32, 2.87, $P=0.0008$ ).

Age group, BMI classification, PASE classification, marital status, living arrangement, education, alcohol consumption, self-rated health and multi-morbidity were not associated with poor nutritional intake. Very few participants were unable to prepare their own meals, to shop for food or received meal service assistance in the previous year; therefore, conclusions cannot be made in relation to associations between these factors and dietary intake. 


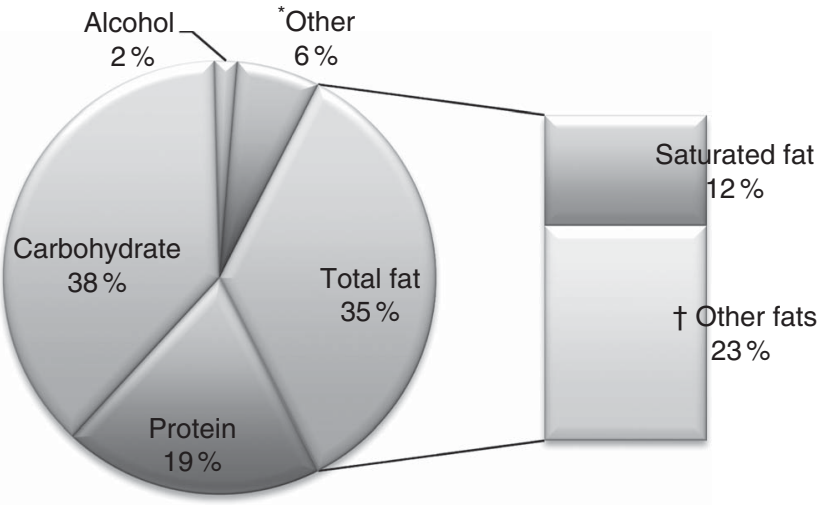

Fig. 1. Macronutrient (\%) distribution of total energy intake of 761 men aged 75 years and over. * Other, sugar alcohol and dietary fibre. † Monounsaturated and polyunsaturated fats.

\section{Discussion}

In this study, we provide the nutritional intake information of the largest and oldest sample of older men ever recruited in Australia. Our findings are comparable with the latest nationally representative Australian Heath Survey (AHS) ${ }^{(21)}$, despite the use of different dietary methodologies in the two studies (AHS used 24-h recall). The similarity of results suggests that nutrition-related findings from CHAMP can be generalised to the Australian population of older men in the very old age group. However, in assessing the findings, it is important to take into account important 'survival effects' - that is, men with poor nutrition are relatively less likely to live to the advanced ages as examined in our study ${ }^{(6)}$.

Although we found that the majority of participants met or exceeded NRV for most nutrients, it was alarming how low the intakes of vitamin $\mathrm{D}$ and $\mathrm{Ca}$ were among our sample. Being born in Italy or Greece was associated with a poor nutritional intake of key nutrients in older men, as was income and occupational history, with pensioners and participants with a history of physically demanding jobs being at higher risk.

These findings suggest a number of areas for targeted interventions. Macronutrient-unbalanced diets may lead to obesity, malnutrition, poor micronutrient intakes and nutritional deficiencies (e.g. anaemia) ${ }^{(30)}$. We observed high total and saturated fat intakes (\%E) and below the recommended level intake of carbohydrates (\%E) among CHAMP participants. Other studies have found similar total fat intakes among older men ${ }^{(11,20,40)}$; one study has found higher intakes ${ }^{(41)}$ and several others have found lower intakes $\mathrm{s}^{(7,21,42,43)}$ compared with our study.

Carbohydrate intakes in our study, both as a proportion of energy and as absolute intake, tended to be lower compared with other studies among older men ${ }^{(11,40-43)}$. However, CHAMP data for carbohydrate intakes were similar to those from older men in the $\mathrm{AHS}^{(21)}$.

Although $72 \%$ of participants met their total energy requirements, it was notable that nearly a third of the participants were at risk in this respect. Assessment of total energy requirements is determined by calculating individuals' BMR - which varies according to body weight, sex and age - and PAL. CHAMP participants' activity levels were measured using the PASE ${ }^{(26)}$, which could not be converted to PAL. As there is no set PAL cut-off for older men, and studies have reported ranges from 1.54 to $1.75^{(44)}$, we chose the mid-point of the range (1.6; light activity) to calculate CHAMP participants' energy requirements.

Sun exposure is the main source of vitamin D for all age groups; however, older people may have insufficient sunlight exposure, and thus nutritional intake of vitamin $\mathrm{D}$ becomes more important. Dietary requirements of vitamin D increase from $5 \mathrm{mcg}$ for males up to 50 years of age to $15 \mathrm{mcg}$ for males aged 71 years and older ${ }^{(30)}$. Very few men in CHAMP achieved their vitamin D requirements; however, adults may find it difficult to obtain more than 5-10\% of their vitamin D requirement from dietary sources in Australia, and if sun exposure is insufficient vitamin D supplementation is recommended for older individuals ${ }^{(45)}$.

Ca intake was also very low among men in CHAMP, with only $19 \%$ reaching the recommendations for this nutrient. Combined, $\mathrm{Ca}$ and vitamin $\mathrm{D}$ are two of the most important nutrients for bone health maintenance ${ }^{(46)}$, and their deficiency is associated with adverse outcomes such as increased incidence of osteoporosis, bone fractures and poor quality of life $^{(46)}$. Low vitamin D and $\mathrm{Ca}$ intakes have been raised as a concern in several other studies of older people ${ }^{(42,43,47)}$.

We found that, although the median intake of $\mathrm{Na}$ was not above the UL of intake, $31 \%$ of participants were consuming potentially harmful amounts of $\mathrm{Na}$. It is important to highlight that participants' Na intake may be higher when considering the extra salt potentially added to food at the time of consumption, which was not measured in the present study. High dietary consumption of $\mathrm{Na}$ can be particularly detrimental to the cardiovascular health of adults; CVD is among the leading causes of death worldwide ${ }^{(48-50)}$.

Breakfast cereal was the main source of many nutrients. In Australia, cereal and cereal products such as wheat flour used in bread are mandatorily fortified with thiamin and folic acid, iodised salt is used to make bread and some other nutrients may be voluntarily added to specific foods ${ }^{(51)}$.

Among the many factors that we assessed, only country of birth and source of income were related to quality of dietary intake, as measured by meeting the NRV for five or more of the seven key nutrients (total energy, protein, $\mathrm{Fe}, \mathrm{Zn}$, riboflavin, $\mathrm{Ca}$ and vitamin D).

A large proportion of CHAMP's participants were born in Italy or Greece (23\%); however, their macronutrient intake distribution was not very different from participants born in Australia and other countries, with the exception of alcohol intake (2.3 v. 1.2\% $)$. Overall, Italian- or Greek-born participants were more likely to have a poor dietary intake of total energy (with a higher proportion of energy coming from alcohol) and virtually all nutrients of interest compared with participants born elsewhere.

Men who received other sources of income (i.e. superannuation, business owners, on a salary, combination of age pension and other sources or other) tended to have a better nutritional intake compared with men with the age pension only. The elevated risk for those on a pension only indicated the importance of income adequacy for purchasing food. An earlier study of older people in NSW found that food insecurity was a significant issue for a small proportion of older men and 
Table 3. Univariate analyses for nutritional intake of key nutrients for older adults and socio-demographic and economic, health and lifestyle and mealrelated activities of daily living (ADL) factors

(Number of subjects and percentages; odds ratios and $95 \%$ confidence intervals)

\begin{tabular}{|c|c|c|c|c|c|c|c|}
\hline \multirow[b]{3}{*}{ Socio-demographic and economic factors } & \multicolumn{4}{|c|}{ Nutritional intake } & & & \multirow[b]{3}{*}{$P$ value } \\
\hline & \multicolumn{2}{|c|}{ Meet } & \multicolumn{2}{|c|}{ Not meet } & \multicolumn{2}{|c|}{ Crude OR $^{*}$} & \\
\hline & $n$ & $\%$ & $n$ & $\%$ & OR & $95 \% \mathrm{Cl}$ & \\
\hline \multicolumn{8}{|l|}{ Age (years) ( $n$ 761) } \\
\hline 75-79 (reference) & 172 & 53 & 155 & 47 & 1.00 & & \multirow[t]{3}{*}{1.00} \\
\hline $80-84$ & 145 & 52 & 132 & 48 & 1.01 & $0.73,1.39$ & \\
\hline $85+$ & 82 & 52 & 75 & 48 & 1.01 & $0.69,1.49$ & \\
\hline \multicolumn{8}{|l|}{ Source of income ( $n 758)$} \\
\hline Pension (reference) & 135 & 46 & 161 & 54 & 1 & & \multirow[t]{2}{*}{0.002} \\
\hline Other & 263 & 57 & 199 & 43 & 0.63 & $0.47,0.85$ & \\
\hline \multicolumn{8}{|l|}{ Occupational history ( $n 757)$} \\
\hline Other (reference) & 345 & 55 & 287 & 45 & 1.00 & & \multirow[t]{2}{*}{0.02} \\
\hline Plant and machine operator/labourer & 54 & 43 & 71 & 57 & 1.58 & $1.07,2.33$ & \\
\hline \multicolumn{8}{|l|}{ Marital status ( $n$ 761) } \\
\hline Married/de facto (reference) & 296 & 52 & 278 & 48 & 1.00 & & \multirow[t]{2}{*}{0.40} \\
\hline Divorced/separated/widowed/never married/other & 103 & 55 & 84 & 45 & 0.87 & $0.62,1.21$ & \\
\hline \multicolumn{8}{|l|}{ Living arrangements $(n 759)$} \\
\hline Live with others (reference) & 317 & 52 & 290 & 48 & 1.00 & & \multirow[t]{2}{*}{$0 \cdot 70$} \\
\hline Lives alone & 82 & 54 & 70 & 46 & 1.07 & $0.75,1.53$ & \\
\hline Post-school qualifications ( $n$ 757) & & & & & & & \\
\hline Bachelor degree or higher (reference) & 72 & 60 & 47 & 40 & 1.00 & & 0.06 \\
\hline Non-university educated & 325 & 51 & 313 & 49 & 1.48 & $0.99,2 \cdot 20$ & \\
\hline Country of birth $(n 754)$ & & & & & & & \\
\hline Australia/New Zealand (reference) & 238 & 58 & 172 & 42 & 1.00 & & $<0.0001$ \\
\hline Italy/Greece & 67 & 38 & 111 & 62 & $2 \cdot 29$ & $1.60,3.29$ & \\
\hline Other & 94 & 54 & 79 & 46 & $1 \cdot 16$ & $0.81,1.66$ & \\
\hline Health and lifestyle factors & & & & & & & \\
\hline PASE (points) ( $n$ 759) & & & & & & & \\
\hline Low activity $(\leq 76)$ (reference) & 123 & 47 & 127 & 52 & 1.00 & & 0.43 \\
\hline Median activity $(77-160)$ & 139 & 53 & 116 & 48 & 0.81 & $0.57,1.15$ & \\
\hline High activity $(\geq 161)$ & 137 & 53 & 117 & 48 & 0.83 & $0.58,1.17$ & \\
\hline BMI $\left(\mathrm{kg} / \mathrm{m}^{2}\right)(n 745)$ & & & & & & & \\
\hline Underweight $(<22 \cdot 0)$ (reference) & 24 & 55 & 20 & 45 & 1.00 & & 0.45 \\
\hline Normal $(22 \cdot 0-30 \cdot 0)$ & 259 & 52 & 243 & 48 & $1 \cdot 12$ & $0.61,2.09$ & \\
\hline Overweight/obese $(>30.0)$ & 113 & 57 & 86 & 43 & 0.91 & $0.47,1.76$ & \\
\hline Alcohol consumption ( $n$ 761) & & & & & & & \\
\hline Non-drinker (reference) & 89 & 50 & 88 & 50 & 1.00 & & 0.80 \\
\hline$\leq 14$ drinks/week & 250 & 53 & 220 & 47 & 0.89 & $0.63,1.26$ & \\
\hline$>14$ drinks/week & 60 & 53 & 54 & 47 & 0.91 & $0.57,1.46$ & \\
\hline Cigarette smoking ( $n$ 753) & & & & & & & \\
\hline Former smoker/never smoked (reference) & 387 & 53 & 342 & 47 & 1.00 & & 0.06 \\
\hline Current smokers & 8 & 33 & 16 & 67 & $2 \cdot 26$ & $0.96,5.35$ & \\
\hline Self-rated health ( $n$ 761) & & & & & & & \\
\hline Excellent/good (reference) & 305 & 54 & 262 & 46 & 1.00 & & 0.20 \\
\hline Fair/poor/very poor & 94 & 48 & 100 & 52 & $1 \cdot 24$ & $0.89,1.72$ & \\
\hline Multi-morbidity ( $n$ 759) & & & & & & & \\
\hline$<2$ (reference) & 105 & 49 & 109 & 51 & 1.00 & & 0.23 \\
\hline $2+$ & 294 & 54 & 251 & 46 & 0.82 & $0.60,1.13$ & \\
\hline Meal-related ADL & & & & & & & \\
\hline Able to grocery shop ( $n 759$ ) & & & & & & & 0.73 \\
\hline Yes (reference) & 391 & 52 & 354 & 48 & 1.00 & & \\
\hline No & 8 & 57 & 6 & 43 & 0.83 & $0.29,2.41$ & \\
\hline Able to prepare own meals ( $n 759)$ & & & & & & & \\
\hline Yes (reference) & 387 & 53 & 340 & 47 & 1.00 & & 0.09 \\
\hline No & 12 & 37 & 20 & 63 & 1.90 & $0.91,3.94$ & \\
\hline Meal service (e.g. MOW) ( $n$ 759) & & & & & & & \\
\hline No (reference) & 389 & 53 & 346 & 47 & 1.00 & & 0.28 \\
\hline Yes & 10 & 42 & 14 & 58 & 1.57 & $0.69,3.59$ & \\
\hline
\end{tabular}

PASE, Physical Activity Scale for the Elderly; MOW, meals on wheels.

* OR of having a poor nutritional intake of key nutrients for older adults - that is, meeting the recommendations for four or less key nutrients.

women $^{(52)}$. However, when asked the question in the past 12 months, was there any time when you could not afford to buy food?', only $1 \%$ of our participants said yes, suggesting that food insecurity was not perceived to be an issue in the overall group, and perhaps nutritional education rather than affordability is a concern in this age group. 
Table 4. Final logistic regression model with adjusted odds ratios for poor nutritional intake (four or less) of key nutrients of interest for older adults (Odds ratios and $95 \%$ confidence intervals)

\begin{tabular}{lccc}
\hline & $\begin{array}{c}\text { Adjusted } \\
\text { OR }\end{array}$ & $95 \% \mathrm{Cl}$ & $P$ \\
\hline Variables & & & 0.08 \\
\hline $\begin{array}{l}\text { Source of income } \\
\quad \text { Pension (reference) }\end{array}$ & 1.00 & - & - \\
$\quad$ Other & 0.75 & $0.55,1.03$ & 0.08 \\
$\begin{array}{l}\text { Occupational history } \\
\quad \text { Other (reference) } \dagger\end{array}$ & 1.00 & - & 0.41 \\
$\quad \begin{array}{l}\text { Plant and machine operator/ } \\
\quad \text { labourer }\end{array}$ & 1.19 & $0.79,1.79$ & - \\
$\begin{array}{l}\text { Country of birth } \\
\quad \text { Australia/New Zealand } \\
\quad \text { (reference) }\end{array}$ & 1.00 & - & 0.003 \\
$\quad$ Italy/Greece & & & - \\
$\quad$ Other & 1.94 & $1.32,2.87$ & 0.0008 \\
& 1.07 & $0.74,1.55$ & 0.74
\end{tabular}

* OR of having a poor nutritional intake of key nutrients for older adults - that is, meeting the recommendations for four or less key nutrients.

† Trade/apprenticeship/certificate/diploma/no qualifications.

A strength of our study was that we used a validated diet history method to assess the nutritional intake of our study population $^{(25)}$. Diet histories obtained by dietitians are a reliable $^{(53,54)}$ approach to capture the dietary intake of individuals over a longer period of time (past 3 months in the present study). Diet histories do not limit the variability of response ${ }^{(54)}$ and have less systematic errors than FFQ, making them more suited to estimate usual nutrient intake. Diet histories are particularly indicated for older people because their diets tend to be consistent over long periods of time and, although it is a retrospective technique, it does not rely on short-term memory and uses a much more interactive approach than other methods $^{(19,55-57)}$. Moreover, diet histories have low respondent burden, which may improve response rates among older people and require no literacy or numeracy skills from participants ${ }^{53,58,59)}$, making them suitable for participants of culturally and linguistically diverse backgrounds. The high response rate to the dietary component of our study (83\%) confirmed that the diet history method is well suited for older men, regardless of country of birth, occupational history, source of income or self-rated health. As with most dietary assessment studies, this study's findings are based on estimation of intake and should be considered as such. There will always be limitations with food composition data, as nutrient content of food is variable and depends on a range of factors ${ }^{(60)}$. In particular, we acknowledge that vitamin $\mathrm{D}$ data reported in this study may be less accurate than the data regarding other nutrients as they were derived from a small set of analyses and values were based on a number of assumptions ${ }^{(28)}$. However, given that they are the most up-to-date data available on vitamin D concentration in foods in Australia ${ }^{(61)}$, we feel that it is important to report participants' intakes through Australian food sources.

In summary, our study of a large population sample of men living in the community in Sydney, Australia, found that the dietary intake of older Australian men is adequate for most of the nutrients analysed (except vitamin D and Ca intakes, which were far below the recommended intakes). However, about half of the participants in this study had a poor nutritional intake of the combined key nutrients for older people.
Being born in Italy or Greece was associated with poor nutritional intake of key nutrients in older men, suggesting the need for nutritional education targeted at older men from culturally and linguistically diverse backgrounds. Men on the age pension had the worst intake of key nutrients for older men, even though the vast majority of men reported no financial issues that prevented them from affording food, which highlights that education and behavioural change - rather than affordability may be the issue in this age group.

These findings suggest a number of avenues for further research and policy action. It seems likely that the nutritional patterns described in this study arise from complex cultural and socio-economic factors that arise earlier in life and persist or change with transitions into later life. The mechanisms leading to nutritional adequacy or risk require further investigation in CHAMP and other longitudinal surveys. Findings on a small but significant number of individuals at nutritional risk indicate the importance of targeted health promotion for ageing and older people as well as examination of the value of meal services and nutritional interventions for clinical populations.

\section{Acknowledgements}

The authors thank all the CHAMP staff and participants for their contributions. The authors thank Ms Nilakshi GunatillakaSamarage for her valuable contribution in data collection.

The CHAMP study is funded by the National Health and Medical Research Council (301916) and the Ageing and Alzheimers Institute. R. V. R. W. and H. V. are funded by the Australian Research Council Centre of Excellence in Population Ageing Research.

R. G. C., F. B. and V. N. designed and developed the project. R. V. R. W., M. A.-F. and R. G. C. designed the protocol for diet history measurement of dietary intake. R. V. R. W. collected the majority of nutritional data and trained the staff for nutritional data collection, conducted all the data analyses and wrote the first draft of the manuscript. V. H. and R. G. C. oversaw the statistical analyses. R. G. C., V. H., F. B., V. N., M. A.-F., D. L. C., H. K. and S. J. S. collaborated in writing. All authors reviewed and approved the final version of the manuscript. All authors had primary responsibility for the final content.

There are no conflicts of interest.

\section{References}

1. World Health Organization (2015) Health topics - ageing. http:// www.who.int/topics/ageing/en/ (accessed March 2015).

2. Australian Bureau of Statistics (2012) Who are Australia's older people? Reflecting a nation: stories from the 2011 census. http://www.abs.gov.au/ausstats/abs@.nsf/lookup/2071.0main+ features752012-2013 (accessed January 2014).

3. Australian Bureau of Statistics (2012) Population size and growth. http://www.abs.gov.au/ausstats/abs@.nsf/Lookup/by \%20Subject/1301.0 2012 Main\%20Features Population\%20 size\%20and\%20growth 47 (accessed February 2014).

4. Mathers JC (2013) Nutrition and ageing: knowledge, gaps and research priorities. Proc Nutr Soc 72, 246-250.

5. Nowson C (2007) Nutritional challenges for the elderly. Nutr Diet 64, S150-S155. 
6. Kendig H, Browning CJ, Thomas SA, et al. (2014) Health, lifestyle, and gender influences on aging well: an Australian longitudinal analysis to guide health promotion. Front Public Health 2, 70 .

7. Löwik M, Westenbrink S, Hulshof K, et al. (1989) Nutrition and aging: dietary intake of 'apparently healthy' elderly (Dutch Nutrition Surveillance System). J Am Coll Nutr 8, 347-356.

8. Wakimoto P \& Block G (2001) Dietary intake, dietary patterns, and changes with age: an epidemiological perspective. J Gerontol A Biol Sci Med Sci 56, 65-80.

9. Morley JE (2001) Decreased food intake with aging. J Gerontol A Biol Sci Med Sci 56, 81-88.

10. Meydani M (2001) Nutrition interventions in aging and ageassociated disease. Ann NY Acad Sci $928,226-235$.

11. Hurson M, Corish C \& Sugrue S (1997) Dietary intakes in Ireland of a healthy elderly population. Ir J Med Sci 166, 220-224.

12. Ahmed T \& Haboubi N (2010) Assessment and management of nutrition in older people and its importance to health. Clin Interv Aging 5, 207-216.

13. Drewnowski A \& Warren-Mears VA (2001) Does aging change nutrition requirements? J Nutr Health Aging 5, 70-74.

14. de Morais C, Oliveira B, Afonso C, et al. (2013) Nutritional risk of European elderly. Eur J Clin Nutr 67, 1215-1219.

15. Wham CA, Teh RO, Robinson M, et al. (2011) What is associated with nutrition risk in very old age? J Nutr Health Aging 15, 247-251.

16. Wham C, Carr R \& Heller F (2011) Country of origin predicts nutrition risk among community living older people. $J$ Nutr Health Aging 15, 253-258.

17. Charlton KE (1999) Elderly men living alone: are they at high nutritional risk? J Nutr Health Aging 3, 42-47.

18. Wylie C, Copeman J \& Kirk S (1999) Health and social factors affecting the food choice and nutritional intake of elderly people with restricted mobility. J Hum Nutr Diet 12, 375-380.

19. Hankin JH (1989) Development of a diet history questionnaire for studies of older persons. Am J Clin Nutr 50, 1121-1127; discussion 1231-1125.

20. Webb KL, Schofield WN, Lazarus R, et al. (1999) Prevalence and socio-demographic predictors of dietary goal attainment in an older population. Aust NZ J Public Health 23, 578-584.

21. Australian Bureau of Statistics (2014) Australian Health Survey: nutrition first results - foods and nutrients, 2011-12. http://www. abs.gov.au/AUSSTATS/abs@.nsf/DetailsPage/4364.0.55.007201112? OpenDocument (accessed September 2014).

22. Cumming RG, Handelsman D, Seibel MJ, et al. (2009) Cohort profile: the Concord Health and Ageing in Men Project (CHAMP). Int J Epidemiol 38, 374-378.

23. Burke BS (1947) The dietary history as a tool in research. J Am Diet Assoc 23, 1041-1046.

24. Williams T (2013) This = That: A Life-Size Photo Guide to Food Serves: Revised and Expanded. Toowong, Australia: FoodTalk.

25. Waern RVR, Cumming R, Travison T, et al. (2015) Relative validity of a diet history questionnaire against a four-day weighed food record among older men in Australia: the Concord Health and Ageing in Men Project (CHAMP). J Nutr Health Aging 19, 603-610.

26. Washburn RA, Smith KW, Jette AM, et al. (1993) The Physical Activity Scale for the Elderly (PASE): development and evaluation. J Clin Epidemiol 46, 153-162.

27. Food Standards Australia New Zealand (2007) AUSNUT 2007, Australian Food, Supplement and Nutrient Database for estimation of population nutrient intakes. http://www.food standards.gov.au/science/monitoringnutrients/ausnut/Pages/ ausnut2007.aspx (accessed March 2014).
28. Food Standards Australia New Zealand (2007) Australian Food, Supplement \& Nutrient Database 2007 for Estimation of Population Nutrient Intakes. Explanatory Notes. Canberra, Australia: Food Standards Australia New Zealand.

29. Schofield WN (1985) Predicting basal metabolic rate, new standards and review of previous work. Hum Nutr Clin Nutr 39, Suppl. 1, 5-41.

30. NHMRC, MoH (2006) Nutrient Reference Values for Australia and New Zealand Including Recommended Dietary Intakes. Canberra: NHMRC.

31. NHMRC (2013) Australian Dietary Guidelines. Canberra: NHMRC.

32. Australian Bureau of Statistics (2015) Australian Health Survey: users' guide, 2011-13. http://www.abs.gov.au/ausstats/abs@. nsf/Lookup/1E3EC1D07846DD78CA257DFF000FA8FB?open document (accessed April 2015).

33. Bannerman E, Miller MD, Daniels LA, et al. (2002) Anthropometric indices predict physical function and mobility in older Australians: the Australian Longitudinal Study of Ageing. Public Health Nutr 5, 655-662.

34. Visvanathan R, Haywood C, Piantadosi C, et al. (2012) Australian and New Zealand Society for Geriatric Medicine: position statement - obesity and the older person. Australas J Ageing 21, 261-267.

35. Berraho M, Nejjari C, Raherison C, et al. (2010) Body mass index, disability, and 13-year mortality in older French adults. J Aging Health 22, 68-83.

36. Sergi G, Perissinotto E, Pisent C, et al. (2005) An adequate threshold for body mass index to detect underweight condition in elderly persons: the Italian Longitudinal Study on Aging (ILSA). J Gerontol A Biol Sci Med Sci 60, 866-871.

37. Kulminski AM, Arbeev KG, Kulminskaya IV, et al. (2008) Body mass index and nine-year mortality in disabled and nondisabled older U.S. individuals. J Am Geriatr Soc 56, 105-110.

38. Winter JE, MacInnis RJ, Wattanapenpaiboon N, et al. (2014) BMI and all-cause mortality in older adults: a meta-analysis. Am J Clin Nutr 99, 875-890.

39. Diederichs C, Berger K \& Bartels DB (2011) The measurement of multiple chronic diseases - a systematic review on existing multimorbidity indices. J Gerontol A Biol Sci Med Sci 66 , 301-311.

40. Volkert D, Kreuel K, Heseker H, et al. (2004) Energy and nutrient intake of young-old, old-old and very-old elderly in Germany. Eur J Clin Nutr 58, 1190-1200.

41. Rothenberg E, Bosaeus I \& Steen B (1993) Intake of energy, nutrients and food items in an urban elderly population. Aging (Milano) 5, 105-116.

42. Dewolfe J \& Millan K (2003) Dietary intake of older adults in the Kingston area. Can J Diet Pract Res 64, 16-24.

43. Marshall TA, Stumbo PJ, Warren JJ, et al. (2001) Inadequate nutrient intakes are common and are associated with low diet variety in rural, community-dwelling elderly. J Nutr 131, 2192-2196.

44. Ritz P (2001) Factors affecting energy and macronutrient requirements in elderly people. Public Health Nutr 4, 561-568.

45. Nowson CA, McGrath JJ, Ebeling PR, et al. (2012) Vitamin D and health in adults in Australia and New Zealand: a position statement. Med J Aust 196, 686-687.

46. Gennari C (2001) Calcium and vitamin D nutrition and bone disease of the elderly. Public Health Nutr 4, 547-559.

47. Foote JA, Giuliano AR \& Harris RB (2000) Older adults need guidance to meet nutritional recommendations. J Am Coll Nutr 19, 628-640.

48. Taylor RS, Ashton KE, Moxham T, et al. (2011) Reduced dietary salt for the prevention of cardiovascular disease: a 
meta-analysis of randomized controlled trials (Cochrane review). Am J Hypertens 24, 843-853.

49. Strazzullo P, D'Elia L, Kandala NB, et al. (2009) Salt intake, stroke, and cardiovascular disease: meta-analysis of prospective studies. Br Med J 339, b4567.

50. World Health Organization (2006) Reducing Salt Intake in Populations - Report of a WHO Forum and Technical Meeting. Paris: World Health Organization.

51. Food Standards Australia New Zealand (2012) Nutrition and fortification - vitamins and minerals added to food. http://www. foodstandards.gov.au/consumer/nutrition/vitaminadded/Pages/ defaultaspx (accessed February 2015)

52. Quine S \& Morrell S (2006) Food insecurity in community-dwelling older Australians. Public Health Nutr 9 , 219-224.

53. Margetts B \& Nelson M (1997) Design Concepts in Nutritional Epidemiology, 2nd ed. New York: Oxford University Press.

54. Gibson RS (2005) Principles of Nutritional Assessment. New York: Oxford University Press.

55. Visser M, LC De Groot, Deurenberg P, et al. (1995) Validation of dietary history method in a group of elderly women using measurements of total energy expenditure. $\mathrm{Br} J$ Nutr $\mathbf{7 4}$, $775-785$

56. McNeill G, Winter J \& Jia X (2009) Diet and cognitive function in later life: a challenge for nutrition epidemiology. Eur J Clin Nutr 63, Suppl. 1, S33-S37.

57. Van Staveren W, Burema J, Livingstone M, et al. (1996) Evaluation of the dietary history method used in the SENECA Study. Eur J Clin Nutr 50, S47-S55.

58. Shahar S, Earland J \& Abdulrahman S (2000) Validation of a dietary history questionnaire against a 7-D weighed record for estimating nutrient intake among rural elderly Malays. Malays J Nutr 6, 33-44.

59. Willett W (1998) Nutritional Epidemiology. New York: Oxford University Press.

60. Pennington JAT (2008) Applications of food composition data: data sources and considerations for use. J Food Comp Anal 21, Suppl., S3-S12.

61. Williams L, Sobolewski R \& Fraser D (2010) Liver and vitamin D: fact or fiction? http://www.foodstandards.gov.au/ media/documents/Liver_Vit\%20D\%20Poster.pdf (accessed March 2015). 